\title{
Estimasi Output Sapi Potong di Kabupaten Pesisir Selatan Provinsi Sumatera Barat
}

\section{The Output Estimation of Beef Cattle Production in Pesisir Selatan District, West Sumatera Province}

\author{
D. E. Putra ${ }^{1}$, Sumadi $^{2}$ dan T. Hartatik ${ }^{2}$ \\ ${ }^{1}$ Department of Genetic and Animal Breeding, Faculty of Animal Science Andalas University Padang 25163 \\ ${ }^{2}$ Department of Animal Breeding and Reproduction, Faculty of Animal Science Universitas Gadjah Mada Yogyakarta \\ 55281 \\ email: dinoekap@yahoo.com \\ (Diterima: 5 Februari 2015; Disetujui: 8 Mei 2015)
}

\begin{abstract}
ABSTRAK
Penelitian ini bertujuan untuk mengidentifikasi produktivitas sapi potong di Kabupaten Pesisir Selatan Provinsi Sumatera Barat dalam menghasilkan bibit sapi potong dan kelayakan daerah tersebut sebagai sumber sapi potong di Provinsi Sumatera Barat. Penelitian ini dilakukan dengan cara sensus dengan alat bantu kuesioner dengan metode Quota sampling digunakan untuk memilih tiga kecamatan yang memiliki populasi tinggi, sedang, dan rendah. Variabel yang diamati dalam penelitian ini adalah identitas peternak dan ternak. Data sekunder dari instansi terkait juga digunakan sebagai pendukung dalam penelitian ini. Perkembangan populasi ternak dianalisis dengan pendekatan teori pemuliabiakan ternak. Rata-rata kenaikan populasi ternak dianalisis menggunakan analisis time series (analisis runtut waktu). Hasil penelitian ini menunjukkan nilai efisiensi reproduksi (ER) sebesar $89,95 \%$ dan nilai natural increase (NI) sebesar 29,46\% yang menunjukkan bahwa pertambahan populasi sapi tergolong sedang. Hasil penelitian ini juga menunjukkan bahwa secara umum populasi sapi potong di Kabupaten Pesisir Selatan masih cukup memenuhi kebutuhan daerah tersebut namun kekurangan ternak pejantan sebesar 12,32\% dan populasi ternak betina melebihi kebutuhan sebesar $21,03 \%$ dengan nilai net replacement rate (NRR) jantan sebesar $87,68 \%$ dan NRR betina sebesar $121,03 \%$. Secara rata-rata output sapi potong pada semua bangsa untuk sapi afkir jantan adalah sebesar 5,93\%, betina sebesar $11,12 \%$, sapi muda jantan sebesar $2,19 \%$, dan sapi muda betina sebesar $1,01 \%$ dari total populasi sapi.
\end{abstract}

Kata kunci: potensi, sapi potong, produktivitas

\section{ABSTRACT}

The research was aimed at identifying the potential of beef cattle production in Pesisir Selatan District of West Sumatra Province and the feasibility of the region as a source of beef cattle. Three sub-districts were selected by high, medium, and low cattle population indicators using quota sampling. Then, three villages were picked up from each sub-district. The variables in this study were the farmer identities and their cattle. Secondary data were collected from related institutions. The dynamic of beef cattle population development was analyzed by using breeding theory approach. The average increase of the population was analyzed by using a time series analysis. The results showed that the efficiency of reproduction (ER) was at $89.95 \%$ and the natural increase (NI) value at 29,46\% indicating a moderate increase of the population The study also showed that the population of the beef cattle in the region was sufficient enough to supply the district owned-need. However, the population of bull was 12,32\% less than the ideal number whereas the population of cows was 21,03\% more than the ideal number. Thus, the net replacement rate (NRR) of the bull was $87,68 \%$ and cows was $121,03 \%$. In detail, the average output of the beef cattle for culled bulls was 5,93\%, cows 11,12\%, steers 2,19\%, and heifers 1,01\% of the total population.

Keywords: beef cattle, output, productivity 


\section{PENDAHULUAN}

Kabupaten Pesisir Selatan merupakan salah satu daerah pengembangan sapi lokal yang dikenal dengan sebutan sapi Pesisir yang pada saat ini populasi sapi di Kabupaten Pesisir Selatan mencapai 78.322 ekor (Badan Pusat Statistik, 2012). Populasi terbesar terdapat di tiga kecamatan yaitu, Kecamatan Linggo Sari Baganti sebanyak 12.865 ekor, Kecamatan Lengayang sebanyak 12.233 ekor dan Kecamatan Sutera sebanyak 11.642 ekor dan sekitar 41.582 ekor tersebar di sembilan kecamatan lainnya di Kabupaten Pesisir Selatan. Sapi potong di Kabupaten Pesisir Selatan telah beradaptasi dan berkembang dengan baik pada sistem peternakan ekstensif tradisional. Sapi dilepaskan sepanjang hari tanpa perhatian khusus dari peternak, serta tahan terhadap lingkungan yang relatif panas, kualitas dan kuantitas pakan yang rendah. Pemeliharaan sapi didominasi peternakan rakyat yang menggunakan sistem konvensional yang memelihara ternak sapi secara dilepas begitu saja dan merupakan usaha sambilan disamping usaha pertanian (Wirdahayati et al. 2006).

Pola pembiakan (breeding) ternak di suatu daerah dapat diketahui dengan melakukan estimasi potensi daerah tersebut sebagai penghasil ternak. Hardjosubroto (1992) menyatakan bahwa penelitian estimasi output adalah untuk mengetahui pola pembiakan dari suatu ternak di suatu daerah. Output sangat dipengaruhi oleh besarnya natural increase (NI). Menurut Hardjosubroto et al. (1990), jumlah output dipengaruhi oleh natural increase, sebab output dihitung berdasarkan selisih antara natural increase dengan kebutuhan ternak pengganti selama satu tahun. Berdasarkan uraian di atas, maka dipandang perlu dilakukan penelitian untuk mengidentifikasi komposisi sapi potong yang dapat dikeluarkan atau yang merupakan potensi atau output setiap tahun di Kabupaten Pesisir Selatan serta untuk mengidentifikasi dinamika populasi sapi potong di Kabupaten Pesisir Selatan Propinsi Sumatera Barat.

\section{METODE}

Penelitian ini telah dilaksanakan di Kabupaten Pesisir Selatan, Propinsi Sumatera Barat dari bulan Agustus 2013 sampai November 2013.

Materi yang digunakan pada penelitian ini adalah petani yang memiliki ternak sapi sebagai responden serta ternak sapi yang tersebar di tiga kecamatan yaitu, 411 responden dari Kecamatan Linggo Sari Baganti, 274 responden dari Kecamatan Batang Kapas dan 332 responden dari Kecamatan Bayang yang merupakan daerah yang memiliki tingkat populasi tinggi, sedang dan rendah di Kabupaten Pesisir Selatan. Adapun jumlah ternak sapi yang digunakan dalam penelitian ini yaitu 677 ekor sapi Bali, 39 ekor sapi PO, 197 ekor sapi SimPO (silangan Simmental dengan PO), 33 ekor sapi SimPes (silangan Simmental dengan Pesisir), 2306 ekor sapi Pesisir dan 6 ekor sapi LimPO (silangan Limosin dengan PO). Adapun peralatan yang digunakan dalam penelitian ini adalah kamera digital dan alat-alat tulis, kuesioner.

Penelitian ini besifat deskriptif analitis dengan metode survei untuk mengumpulkan data primer dan sekunder. Cara pengumpulan data primer dilakukan dengan wawancara langsung kepada peternak responden, sedangkan data sekunder diambil dari Dinas Peternakan di Kabupaten Pesisir Selatan. Pengambilan sampel dilakukan dengan cara purpossive sampling dan quota sampling terhadap peternak dan ternak sapi pada masing-masing kecamatan.

Data primer yang diambil meliputi identitas peternak dan data reproduksi ternak sapi. Data identitas dari peternak meliputi umur peternak, pengalaman lama beternak, tingkat pendidikan, tujuan pemeliharaan, dan sistem pemeliharaan yang dilakukan. Data reproduksi ternak sapi yang diambil terdiri dari perkawinan, lama induk dan pejantan yang digunakan dalam pembiakan, kelahiran, kematian, jumlah ternak yang disurvei, dan struktur populasi. Data sekunder yang dikumpulkan adalah data populasi, pemasukan, pengeluaran, dan pemotongan 
dari Dinas Peternakan Kabupaten Pesisir Selatan.

\section{Analisis Data}

Data yang diperoleh ditabulasi dan dianalisis pada masing-masing bangsa dengan cara: data identitas peternak secara deskriptif kuantitatif. Data identitas ternak dianalisis dengan menghitung persentase dan rata-rata sehingga dapat menghasilkan koefisien teknis yang dapat digunakan untuk menghitung natural increase, net replacement rate, dan output sapi potong.

Efisiensi Reproduksi (ER) dihitung dengan cara:

$$
\mathrm{ER}=\frac{(\mathrm{A}) \text { (jumlah anak })}{(1 \mathrm{kali} \text { beranak })-(1 \mathrm{kali} \mathrm{kawin})+\mathrm{A}-(\mathrm{B})} \times 100 \%
$$

Keterangan:

$\mathrm{A}=$ jarak beranak

$\mathrm{B}=$ lama bunting

Natural increase dihitung dengan cara:

\section{$\mathrm{NI}=\%$ kelahiran pertahun $-\%$ kematian pertahum}

Nilai net replacement rate (NRR) dihitung dengan cara:

Diperoleh dari perbandingan jumlah ternak muda calon pengganti dibagi dengan kebutuhan ternak pengganti per tahun dikalikan 100\%. Nilai NRR digunakan untuk mengetahui apakah jumlah kelahiran ternak dapat menutupi kebutuhan akan ternak pengganti agar supaya populasi tetap konstan. Jika NRR < 100\% maka kebutuhan ternak pengganti tidak terpenuhi, sebaliknya apabila NRR > 100\% maka kebutuhan ternak pengganti tercukupi (Sumadi, 2001).

Populasi dihitung dengan rumus:

$$
\{(\mathrm{N}(\text { awal })+\mathrm{N}(\text { akhir })) / 2\}
$$

Dimana populasi awal dihitung dengan rumus:

$$
\mathrm{N}\left(\text { awal) }=\mathrm{N} \text { (akhir) }+\mathrm{Di}+\mathrm{G} \_\mathrm{Bi}-\mathrm{E}\right.
$$

\section{Keterangan:}

$$
\begin{array}{ll}
\mathrm{N}(\text { awal) } & \text { jumlah populasi awal (ekor) } \\
\mathrm{N} & =\text { jumlah populasi (ekor) } \\
\mathrm{N}(\text { akhir) } & =\text { jumlah populasi akhir (ekor) } \\
\mathrm{Di} & =\text { jumlah kematian terhadap } \\
& \text { populasi setahun (ekor) } \\
\mathrm{G} & =\text { jumlah pengeluaran selama }
\end{array}
$$

$\mathrm{Bi}$

E

$=$ jumlah kelahiran pedet terhadap populasi (ekor)

$=$ jumlah ternak yang masuk selama setahun (ekor)

Estimasi output diperoleh dianalisis pada setiap populasi dengan cara dihitung berdasarkan jumlah ternak yang tersingkirkan tiap tahun dan jumlah sisa ternak pengganti. Data diperoleh dari perhitungan data pola pengembangbiakan sapi jantan dan sapi betina, yaitu menggunakan rekaan kompetisi berdasarkan kelompok umur :

Potensi ternak $=$ sisa replacement - target kenaikan populasi + ternak jantan dan betina afkir

\section{HASIL DAN PEMBAHASAN}

\section{Identitas peternak}

Identitas peternak merupakan salah satu indikasi yang dapat digunakan untuk mengetahui kemampuan peternak dalam mengelola ternak, antara lain umur peternak, lama beternak, tingkat pendidikan dan mata pencaharian. Pada Tabel 1 menunjukkan masing-masing bangsa sapi bahwa rata-rata umur peternak di Kabupaten Pesisir Selatan, Provinsi Sumatera Barat berada pada kisaran umur produktif $(44,24 \pm 3,21$ tahun $)$ dan pengalaman beternak cukup lama $(9,34 \pm 2,69$ tahun). Berdasarkan hasil penelitian peternak masih dalam usia produktif dan cukup berpengalaman dalam mengelola peternakan, sehingga dapat memecahkan masalah dalam mengelola peternakan sapi potong sesuai dengan kondisi setempat. Pengalaman beternak juga merupakan salah satu tolak ukur bagi kemajuan usaha peternakan, karena semakin lama beternak maka peternak akan lebih mampu untuk menyelesaikan kesulitan dan hambatan dalam mengelola usaha peternakan (Widiyanti, 1987).

Tingkat pendidikan peternak di Kabupaten Pesisir Selatan, Provinsi Sumatera Barat sangat bervariasi mulai yang tidak tamat sekolah dasar atau tidak pernah menempuh pendidikan formal sampai dengan perguruan tinggi. 
Tabel 1. Identitas peternak sapi potong di Kabupaten Pesisir Selatan Provinsi Sumatera Barat tahun 2013 (the identity of farmer in Pesisir Selatan District of West Sumatera Province 2013)

\begin{tabular}{|c|c|c|c|c|c|c|c|c|}
\hline \multirow{2}{*}{$\begin{array}{c}\mathrm{N} \\
\mathrm{o}\end{array}$} & \multirow{2}{*}{ Peubah (variables) } & \multicolumn{6}{|c|}{ Bangsa (breed) } & \multirow{2}{*}{$\begin{array}{c}\text { Rata-rata } \\
\text { (mean) } \\
\pm \text { STD }\end{array}$} \\
\hline & & Bali & $\mathrm{PO}$ & SimPO & SimPes & Pesisir & LimPO & \\
\hline 1 & $\begin{array}{l}\text { Umur Peternak (tahun) (farmers old } \\
(\text { years)) }\end{array}$ & 43,36 & 46,04 & 45,76 & 47,88 & 43,82 & 38,60 & $44,24 \pm 3,21$ \\
\hline 2 & $\begin{array}{l}\text { Pengalaman Beternak (tahun) } \\
\text { (farmers experience(years)) }\end{array}$ & 7,10 & 11,24 & 11,72 & 11,54 & 9,25 & 5,20 & $9,34 \pm 2,69$ \\
\hline \multirow[t]{6}{*}{3} & $\begin{array}{l}\text { Pendidikan }(\%) \text { (farmers education } \\
(\%) \text { ) }\end{array}$ & & & & & & & \\
\hline & a. Tidak sekolah (uneducation) & 10,56 & 8,00 & 14,17 & 3,85 & 16,11 & 0,00 & $8,78 \pm 6,13$ \\
\hline & b. SD (primary school) & 32,22 & 16,00 & 23,33 & 19,23 & 30,39 & 0,00 & $20,20 \pm 11,70$ \\
\hline & c. SMP/SLTP (junior high school) & 41,11 & 40,00 & 22,50 & 23,07 & 36,41 & 40,00 & $33,8 \overline{5} \pm 8,72$ \\
\hline & d. SMU (senior high school) & 15,56 & 36,00 & 33,33 & 50,00 & 16,39 & 60,00 & $35,21 \pm 17,76$ \\
\hline & $\begin{array}{l}\text { e. Perguruan Tinggi (higher } \\
\text { education/university) }\end{array}$ & 0,55 & 0,00 & 6,67 & 3,85 & 0,70 & 0,00 & $1,96 \pm 2,72$ \\
\hline \multirow[t]{5}{*}{4} & Pekerjaan Utama $(\%)($ job $(\%))$ & & & & & & & \\
\hline & a. Petani (farmers) & 93,33 & 88,00 & 95,83 & 84,61 & 97,19 & 80,00 & $89,83 \pm 6,78$ \\
\hline & $\begin{array}{l}\text { b. Pegawai Negeri Sipil (goverment } \\
\text { staff) }\end{array}$ & 1,11 & 0,00 & 1,67 & 3,85 & 0,56 & 0,00 & $1,20 \pm 1,45$ \\
\hline & c. Wiraswasta (enterpreneur) & 5,56 & 8,00 & 1,28 & 11,54 & 2,11 & 20,00 & $8,08+6,96$ \\
\hline & d. Swasta (private) & 0,00 & 4,00 & 1,67 & 0,00 & 0,14 & 0,00 & $0,97 \pm 1,62$ \\
\hline \multirow[t]{3}{*}{5} & $\begin{array}{l}\text { Tujuan Utama Pemeliharaan (\%) } \\
\text { (farming aim }(\%) \text { ) }\end{array}$ & & & & & & & \\
\hline & a. Keturunan (breeding) & 100,00 & 100,00 & 90,84 & 88,46 & 100,00 & 100,00 & $96,55 \pm 5,40$ \\
\hline & b. Penggemukan (feedlot) & 0,00 & 0,00 & 9,16 & 11,54 & 0,00 & 0,00 & $3,45 \pm 1,68$ \\
\hline
\end{tabular}

Pada penelitian ini peternak yang tidak tamat SD, SD, SLTP, SMU dan perguruan tinggi secara berturut-turut adalah sebesar $8,78 \pm 6,13 \%, \quad 20,20 \pm 11,70 \%, \quad 33,85 \pm 8,72 \%$, $35,21 \pm 17,76 \%$ dan $1,96 \pm 2,72 \%$. Lebih dari $50 \%$ peternak sudah menempuh pendidikan sembilan tahun, sehingga inovasi-inovasi dalam pengembangan peternakan sangat mudah diterapkan di lokasi penelitian ini. Dari sisi mata pencaharian utama, sebagian besar peternak berprofesi sebagai petani $(89,83 \pm 6,78 \%) \quad$ sehingga kondisi ini merupakan aset yang positif untuk mendukung keberhasilan tani ternak potong di kabupaten Pesisir Selatan.

\section{Mutasi Sapi Potong}

Mutasi yang dimaksud dalam penelitian ini adalah mutasi ternak antar peternak dalam wilayah yang sama atau pada wilayah yang berbeda. Proses mutasi dapat berlangsung melalui jual beli antar peternak atau dapat juga berlangsung dengan proses penjualan ternak untuk dipotong. Sapi yang keluar lebih banyak dari sapi yang masuk, hal ini diduga ada kemungkinan bahwa Kabupaten Pesisir Selatan adalah sumber bibit sapi potong untuk kawasan Sumatera Barat, serta kecenderungan masyarakat untuk menjual sapinya disaat hari raya besar, terutama hari raya Idul Adha. Tabel 2 menunjukkan mutasi sapi potong dari setiap bangsa di Kabupaten Pesisir Selatan Provinsi Sumatera Barat tahun 2013 dan jumlah sapi yang masuk dari semua bangsa sapi potong.

Pada penelitian ini mutasi sapi potong dari setiap bangsa di Kabupaten Pesisir Selatan tahun 2013 dan jumlah sapi yang masuk dari semua bangsa sapi potong dengan rata-rata sebanyak 79 ekor atau sebesar 2,51\% terhadap populasi dan jumlah yang keluar dari semua bangsa sapi potong dengan rata-rata sebanyak 178 ekor atau sebesar 5,62\% dari total populasi. Salah satu tolak ukur bahwa suatu wilayah merupakan penghasil ternak sapi adalah perbedaan persentase ternak yang keluar dan yang masuk dalam suatu wilayah (Budiarto, 1991). 
Tabel 2. Mutasi sapi potong di Kabupaten Peisir Selatan Provinsi Sumatera Barat tahun 2013 (mutations beef cattle in Pesisir Selatan District of West Sumatera Province 2013)

\begin{tabular}{|c|c|c|c|c|c|c|c|c|}
\hline \multirow[b]{2}{*}{ No } & \multirow[b]{2}{*}{ Komposisi } & \multicolumn{6}{|c|}{ Bangsa (breed) } & \multirow{2}{*}{$\begin{array}{l}\text { Semua } \\
\text { Bangsa (all } \\
\text { breed) }\end{array}$} \\
\hline & & Bali & $\mathrm{PO}$ & SimPO & SimPes & Pesisir & LimPO & \\
\hline \multirow[t]{9}{*}{1} & Masuk (ekor) (sign in (head)) & & & & & & & \\
\hline & $\begin{array}{l}\text { a. Pedet (calf) } \\
\quad \operatorname{Jantan}(\text { male })\end{array}$ & 0 & 0 & 0 & 0 & 0 & 0 & 0 \\
\hline & Betina (female) & 4 & 0 & 0 & 0 & 64 & 0 & 68 \\
\hline & $\begin{array}{l}\text { b. Muda (young) } \\
\text { Jantan (male) }\end{array}$ & 1 & 0 & 0 & 0 & 11 & 0 & 12 \\
\hline & Betina (female) & 0 & 0 & 0 & 0 & 0 & 0 & 0 \\
\hline & $\begin{array}{l}\text { c. Dewasa (adult) } \\
\text { Jantan (male) }\end{array}$ & 0 & 0 & 0 & 0 & 0 & 0 & 0 \\
\hline & Betina (female) & 0 & 0 & 0 & 0 & 0 & 0 & 0 \\
\hline & Jumlah (total) & 5 & 0 & 0 & 0 & 75 & 0 & 80 \\
\hline & $\begin{array}{l}\text { Jumlah sapi masuk terhadap } \\
\text { populasi (\%) (total of beef cattle } \\
\text { entering the population }(\%))\end{array}$ & 0,76 & 0,00 & 0,00 & 0,00 & 3,25 & 0,00 & 2,46 \\
\hline \multirow[t]{9}{*}{2} & Keluar (ekor) (exit (head)) & & & & & & & \\
\hline & $\begin{array}{l}\text { a. Pedet (calf) } \\
\quad \text { Jantan (male) }\end{array}$ & 14 & 1 & 14 & 0 & 175 & 0 & 85 \\
\hline & Betina (female) & 8 & 0 & 6 & 2 & 32 & 0 & 48 \\
\hline & $\begin{array}{l}\text { b. Muda (young) } \\
\text { Jantan (male) }\end{array}$ & 12 & 1 & 4 & 1 & 15 & 0 & 33 \\
\hline & Betina (female) & 2 & 0 & 0 & 0 & 3 & 0 & 6 \\
\hline & $\begin{array}{l}\text { c. Dewasa (adult) } \\
\text { Jantan (male) }\end{array}$ & 0 & 0 & 1 & 0 & 4 & 0 & 5 \\
\hline & Betina (female) & 1 & 0 & 0 & 0 & 0 & 0 & 1 \\
\hline & Jumlah (total) & 38 & 2 & 25 & 3 & 110 & 0 & 178 \\
\hline & $\begin{array}{l}\text { Jumlah sapi masuk terhadap } \\
\text { populasi }(\%) \text { (total of beef cattle } \\
\text { entering the population }(\%))\end{array}$ & 5,76 & 5,56 & 16,03 & 9,09 & 4,77 & 0,00 & 5,46 \\
\hline 3 & Populasi sapi (cattle population) & 677 & 39 & 197 & 33 & 2306 & 6 & 3258 \\
\hline
\end{tabular}

Keterangan: Pedet $=1$ sampai 11 bulan, Muda $=12$ bulan sampai 24 bulan, Dewasa $=>24$ bulan

\section{Komposisi dan struktur populasi sapi potong}

Komposisi dan struktur populasi sapi potong (Tabel 3) dari setiap bangsa di Kabupaten Pesisir Selatan Provinsi Sumatera Barat tahun 2013 yang menunjukkan bahwa komposisi sapi potong di Kabupaten Pesisir Selatan Provinsi Sumatera Barat sebagian besar adalah sapi Pesisir $(70,78 \%)$ kemudian sapi Bali (20,77\%), sapi SimPO (6,05\%), SimPes $(1,01 \%)$, PO $(1,20 \%)$ dan LimPO $(0,18 \%)$. Struktur populsai berdasarkan statusnya yaitu dewasa, muda dan pedet pada semua bangsa sapi pada kondisi normal dengan jumlah sapi dewasa sebesar $48,77 \%$, muda sebesar $24,56 \%$ dan pedet sebesar
26,67\%. Struktur populasi sapi potong pada penelitian ini berbeda dengan dengan hasil penelitian yang dilakukan oleh Tanari et al. (2011) di Kecamatan Pamona Utara Kabupaten Poso yang memperoleh perbandingan sebesar $70 \%$ sapi dewasa, $15 \%$ sapi muda dan $15 \%$ sapi pedet. Pada sapi dewasa jumlah betina relatif tinggi dalam populasi pada penelitian ini, maka sangat mendukung dalam program breeding oleh peternakan rakyat. Persentase kelahiran pedet betina juga relatif tinggi dibandingkan jumlah kelahiran pedet jantan, hal ini merupakan komposisi yang baik untuk replacement stock.

Rata-rata kepemilikan sapi potong per peternak adalah 2,11 UT, artinya dua ekor 
Tabel 3. Komposisi dan struktur populasi serta kepemilikan sapi potong di Kabupaten Pesisir Selatan Provinsi Sumatera Barat tahun 2013 (the composition of beef cattle in Pesisir Selatan District West Sumatera 2013)

\begin{tabular}{|c|c|c|c|c|c|c|c|c|}
\hline \multirow{2}{*}{ No } & \multirow{2}{*}{ Komposisi (composition) } & \multicolumn{6}{|c|}{ Bangsa (breed) } & \multirow{2}{*}{$\begin{array}{c}\text { Jumlah } \\
\text { (total) }\end{array}$} \\
\hline & & Bali & $\mathrm{PO}$ & SimPO & SimPes & Pesisir & LimPO & \\
\hline \multirow[t]{10}{*}{1} & Dewasa $(a d u l t)$ & & & & & & & \\
\hline & a. Jantan (male) (ek) & 21 & 0 & 7 & 3 & 58 & 0 & 89 \\
\hline & $(\mathrm{UT})$ & 21 & 0,00 & 7,00 & 3,00 & 58,00 & 0,00 & 89,00 \\
\hline & $(\%)$ & 3,10 & 0,00 & 3,55 & 9,09 & 2,52 & 0,00 & 2,73 \\
\hline & b. Betina $($ female $)(\mathrm{ek})$ & 314 & 24 & 101 & 8 & 1050 & 3 & 1500 \\
\hline & (UT) & 314,00 & 24,00 & 101,00 & 8,00 & 1050,00 & 3,00 & 1500,00 \\
\hline & $(\%)$ & 47,08 & 61,54 & 51,27 & 24,24 & 45,53 & 50,00 & 46,04 \\
\hline & c. Jumlah (total) (ek) & 335 & 24 & 108 & 11 & 1108 & 3 & 1589 \\
\hline & (UT) & 335,00 & 24,00 & 108,00 & 11,00 & 1108,00 & 3,00 & 1589,00 \\
\hline & $(\%)$ & 49,48 & 61,54 & 54,82 & 33,33 & 48,05 & 50,00 & 48,77 \\
\hline \multirow[t]{10}{*}{2} & Muda (young) & & & & & & & \\
\hline & a. Jantan (male) (ek) & 80 & 3 & 19 & 7 & 187 & 0 & 296 \\
\hline & (UT) & 48,00 & 1,80 & 11,40 & 4,20 & 112,20 & 0,00 & 177,60 \\
\hline & $(\%)$ & 11,82 & 7,69 & 9,94 & 21,21 & 8,11 & 0,00 & 9,09 \\
\hline & b. Betina (female) (ek) & 101 & 6 & 28 & 10 & 357 & 2 & 504 \\
\hline & (UT) & 60,60 & 3,60 & 16,80 & 6,00 & 214,20 & 1,20 & 302,40 \\
\hline & $(\%)$ & 14,92 & 15,38 & 14,21 & 30,30 & 15,48 & 33,33 & 15,47 \\
\hline & c. Jumlah (total) (ek) & 181 & 9 & 47 & 17 & 544 & 2 & 800 \\
\hline & (UT) & 108,60 & 5,40 & 28,20 & 10,20 & 326,40 & 1,20 & 480,00 \\
\hline & $(\%)$ & 26,74 & 37,07 & 24,15 & 51,51 & 23,59 & 33,33 & 24,56 \\
\hline \multirow[t]{10}{*}{3} & Pedet (calf) & & & & & & & \\
\hline & a. Jantan (male) (ek) & 76 & 4 & 26 & 3 & 334 & 1 & 444 \\
\hline & $(\mathrm{UT})$ & 19,00 & 1,00 & 6,50 & 0,75 & 83,50 & 0,25 & 111 \\
\hline & $(\%)$ & 11,23 & 10,26 & 13,20 & 9,09 & 14,48 & 16,67 & 13,63 \\
\hline & b. Betina (female) (ek) & 85 & 2 & 16 & 2 & 320 & 0 & 425 \\
\hline & (UT) & 21,25 & $0, \overline{5}$ & 4 & 0,5 & 80,00 & 0,00 & 106,25 \\
\hline & $(\%)$ & 11,55 & 5,13 & 8,12 & 6,06 & 13,88 & 0,00 & 13,04 \\
\hline & c. Jumlah (total) (ek) & 161 & 6 & 42 & 5 & 654 & 1 & 869 \\
\hline & $(\mathrm{UT})$ & 40,25 & 1,50 & 10,50 & 1,25 & 163,50 & 0,25 & 217,25 \\
\hline & $(\%)$ & 23,78 & 15,39 & 21,32 & 15,15 & 28,36 & 16,67 & 26,67 \\
\hline \multirow[t]{9}{*}{4} & Jumlah (total) (ek) & 677 & 39 & 197 & 33 & 2306 & 6 & 3258 \\
\hline & $(\mathrm{UT})$ & 483,90 & 30,90 & 146,70 & 22,45 & 1597,90 & 4,45 & 2286,25 \\
\hline & $(\%)$ & 20,77 & 1,20 & 6,05 & 1,01 & 70,78 & 0,18 & 100,00 \\
\hline & a. Jantan (male) (ek) & 177 & 7 & 52 & 13 & 579 & 1 & 829 \\
\hline & (UT) & 88,00 & 2,80 & 24,90 & 7,95 & 253,70 & 0,25 & 377,60 \\
\hline & $(\%)$ & 26,14 & 17,95 & 26,80 & 39,39 & 25,11 & 16,67 & 25,45 \\
\hline & b. Betina (female) (ek) & 500 & 32 & 145 & 20 & 1727 & 5 & 2429 \\
\hline & (UT) & 395,90 & 28,10 & 121,80 & 14,50 & 1344,2 & 4,20 & 1908,65 \\
\hline & $(\%)$ & 73,86 & 82,05 & 73,20 & 60,61 & 74,89 & 83,33 & 74,55 \\
\hline 5 & $\begin{array}{l}\text { Jumlah responden (total } \\
\text { respondent) }\end{array}$ & 181 & 25 & 120 & 26 & 711 & 5 & 1068 \\
\hline \multirow[t]{2}{*}{6} & $\begin{array}{l}\text { Pemilikan /responden } \\
\text { (ownership/respondent) (ek) }\end{array}$ & 3,74 & 1,56 & 1,64 & 1,27 & 3,24 & 1,2 & 3,05 \\
\hline & $(\mathrm{UT})$ & 2,67 & 1,24 & 1,22 & 0,86 & 2,25 & 0,74 & 2,11 \\
\hline
\end{tabular}

Keterangan: Pedet $=1$ sampai 11 bulan, Muda $=12$ bulan sampai 24 bulan, Dewasa $=>24$ bulan

dewasa, satu ekor pedet. Apabila dilihat kepemilikan sapi per peternak pada setiap bangsa sapi adalah Bali sebesar 2,67 UT, PO sebesar 1,24 UT, SimPO sebesar 1,22 UT, SimPes sebesar 0,86 UT, Pesisir sebesar 2,25 UT dan LimPO sebesar 0,74 UT.

\section{Penampilan reproduksi}

Informasi tentang reproduksi ternak sapi diperlukan untuk mengetahui kemampuan repr-roduksi suatu ternak. Tabel 4 menunjukkan data beberapa sifat reproduksi 
Tabel 4. Data reproduksi sapi potong di Kabupaten Pesisir Selatan Provinsi Sumatera Barat tahun 2013 (data reproduction of beef cattle in Pesisir Selatan District of West Sumatera 2013)

\begin{tabular}{|c|c|c|c|c|c|c|c|c|}
\hline \multirow{2}{*}{ No } & \multirow{2}{*}{ Peubah (variable) } & \multicolumn{6}{|c|}{ Bangsa (breed) } & \multirow{2}{*}{$\begin{array}{l}\text { Rata-rata } \\
(\text { mean }) \pm \text { std }\end{array}$} \\
\hline & & Bali & $\mathrm{PO}$ & SimPO & SimPes & Pesisir & LimPO & \\
\hline \multirow[t]{3}{*}{1} & Umur pertama kali kawin (first matin & $\lg$ old $(n$ & onth)) & & & & & \\
\hline & a. Jantan (male) & 26,48 & 23,04 & 19,62 & 21,63 & 20,75 & 24,50 & $22,67 \pm 2,53$ \\
\hline & b. Betina (female) & 21,42 & 24,15 & 20,97 & 23,50 & 24,40 & 23,67 & $23,02 \pm 1,46$ \\
\hline \multirow[t]{4}{*}{2} & Cara kawin $(\%)$ (mating method $(\%)$ ) & & & & & & & \\
\hline & a. Inseminasi buatan (IB) $(A I)$ & 5,56 & 64,00 & 89,17 & 53,85 & 7,74 & 100,00 & $53,39 \pm 39,84$ \\
\hline & b. Alam (natural) & 91,11 & 8,00 & 0,00 & 19,23 & 89,45 & 0,00 & $34,63 \pm 43,68$ \\
\hline & c. Campuran (mixed) & 3,33 & 28,00 & 10,83 & 26,92 & 2,81 & 0,00 & $11,98 \pm 12,52$ \\
\hline \multirow[t]{5}{*}{3} & Pengenalan tanda birahi (\%) (introdu & ction of & estru) & & & & & \\
\hline & a. Kurang (less) & 51,67 & 20,00 & 20,83 & 46,15 & 44,16 & 33,33 & $36,02 \pm 13,48$ \\
\hline & b. Sedang (medium) & 39,44 & 36,00 & 36,67 & 34,62 & 38,82 & 66,67 & $42,04 \pm 12,20$ \\
\hline & c. Baik (good) & 8,89 & 44,00 & 34,17 & 19,23 & 13,36 & 0,00 & $19,94 \pm 16,40$ \\
\hline & d. Baik sekali (very good) & 0,00 & 0,00 & 8,33 & 0,00 & 3,66 & 0,00 & $2,00 \pm 3,43$ \\
\hline \multirow[t]{4}{*}{4} & Batas umur pemeliharaan (th) (maxin & num of $\mathrm{c}$ & ld to bre & eding(year & & & & \\
\hline & a. Jantan (male) & 2,51 & 2,42 & 2,61 & 2,29 & 2,52 & 2,10 & $2,41 \pm 0,19$ \\
\hline & b. Betina (female) & 6,40 & 6,72 & 6,73 & 5,81 & 6,44 & 7,20 & $6,55 \pm 0,46$ \\
\hline & $\begin{array}{l}\text { c. Frekuensi beranak (kali) (partus } \\
\text { frequency) }\end{array}$ & 2,42 & 2,64 & 2,67 & 2,31 & 2,71 & 2,00 & $2,46 \pm 0,27$ \\
\hline 5 & $\begin{array}{l}\text { Umur penyapihan (bulan) (old of } \\
\text { weaning (month)) }\end{array}$ & 5,57 & 5,16 & 5,81 & 5,31 & 5,56 & 6,00 & $5,57 \pm 0,31$ \\
\hline 6 & $\begin{array}{l}\text { Umur induk pertama kali beranak } \\
\text { (bulan) (first parent old (month)) }\end{array}$ & 32,95 & 34,75 & 33,09 & 35,65 & 32,20 & 34,33 & $33,83 \pm 1,30$ \\
\hline 7 & $\begin{array}{l}\text { Perkawinan pertama setelah } \\
\text { beranak (bulan) (first mating after } \\
\text { birth (month)) }\end{array}$ & 4,91 & 4,65 & 5,35 & 5,72 & 5,10 & 6,00 & $5,30 \pm 0,51$ \\
\hline 8 & Service per conception $(\mathrm{S} / \mathrm{C})$ & 1,73 & 1,50 & 1,86 & 1,64 & 1,40 & 1,67 & $1,63 \pm 0,16$ \\
\hline 9 & $\begin{array}{l}\text { Jarak beranak (bulan) (calving } \\
\text { interval (month)) }\end{array}$ & 15,64 & 15,63 & 15,86 & 16,35 & 15,70 & 18,00 & $16,20 \pm 0,92$ \\
\hline \multirow[t]{4}{*}{10} & Kondisi induk setelah melahirkan $(\%$ & )$(\operatorname{sow} \mathrm{c}$ & ondition & at calving & $\%))$ & & & \\
\hline & a. Kurus (thin) & 22,72 & 25,00 & 20,93 & 52,18 & 64,71 & 0,00 & $30,92 \pm 23,46$ \\
\hline & b. Sedang (medium) & 59,10 & 75,00 & 60,47 & 39,13 & 29,41 & 100,00 & $60,52 \pm 25,28$ \\
\hline & c. Gemuk $(f a t)$ & 18,18 & 0,00 & 18,60 & 8,69 & 5,88 & 0,00 & $8,56 \pm 8,33$ \\
\hline
\end{tabular}

sapi potong Kabupaten Peisir Selatan Provinsi Sumatera Barat tahun 2013.

Tabel 4 menunjukkan bahwa peternak sapi potong di Kabupaten Pesisir Selatan Provinsi Sumatera Barat mempunyai kemampuan untuk mengenal tanda-tanda birahi secara baik sekali dan baik sebesar $21,94 \%$, sebagian besar kurang dan sedang sebesar 78,06\%. Rata-rata umur pertama kali kawin sapi potong di Kabupaten Pesisir Selatan Provinsi Sumatera Barat pada sapi jantan dan betina masing-masing 22,67 $\pm 2,53$ bulan dan 23,02 $\pm 1,46$ bulan. Hasil ini lebih rendah dibandingkan dengan hasil penelitian yang dilakukan oleh Tanari et al. (2011) 30,60 bulan pada sapi jantan dan 28,20 bulan pada sapi betina, Susanti et al. (2015) 26,21 $\pm 0,47$ bulan pada sapi jantan dan $23,24 \pm 0,72$ bulan pada sapi betina.

Sapi potong di Kabupaten Pesisir Selatan Provinsi Sumatera Barat dikawinkan secara IB sebanyak 53,39\%, dikawinkan secara alami sebanyak 34,63\% dan kawin campuran sebanyak $11,98 \%$. Beda halnya dengan hasil penelitian yang dilakukan oleh Susanti et al. (2015) yang memperoleh cara kawin ternak sapi di Kabupaten Banyuasin didominasi dengan cara kawin alam yaitu sebesar 75,46 $\pm 17,16 \%$. Pada sapi lokal seperti sapi Pesisir dan sapi Bali rata-rata dikawinkan secara alami, yaitu sebanyak 89,45 dan $91,11 \%$, ini dikarenakan untuk menjaga kemurnian genetik sapi lokal itu sendiri. Sapi betina pada penelitian ini untuk menjadi bunting memerlukan sebanyak 1,63 
Tabel 5. Natural increase sapi potong di Kabupaten Pesisir Selatan Provinsi Sumatera Barat tahun 2013 (NI of beef cattle in Pesisir Selatan District West Sumatera Province 2013)

\begin{tabular}{|c|c|c|c|c|c|c|c|c|}
\hline \multirow{2}{*}{$\begin{array}{l}\mathrm{N} \\
\mathrm{O}\end{array}$} & \multirow[b]{2}{*}{ Peubah (variable) } & \multicolumn{6}{|c|}{ Bangsa (breed) } & \multirow{2}{*}{$\begin{array}{l}\text { Semua } \\
\text { bangsa } \\
\quad(\text { all } \\
\text { breed })\end{array}$} \\
\hline & & Bali & $\mathrm{PO}$ & SimPO & SimPes & Pesisir & LimPO & \\
\hline 1 & $\begin{array}{l}\text { Populasi rata-rata (average } \\
\text { population) }\end{array}$ & 615,5 & 37 & 189 & 32 & 2004,5 & 5,5 & 2883,5 \\
\hline 2 & $\begin{array}{l}\text { Populasi induk (ekor) (parent } \\
\text { population) }\end{array}$ & 314 & 24 & 101 & 8 & 1050 & 3 & 1500 \\
\hline 3 & $\begin{array}{l}\text { Populasi induk terhadap populasi } \\
\text { rata-rata }(\%) \text { (parent population of } \\
\text { the average population) }\end{array}$ & 51,02 & 64,86 & 53,44 & 25 & 52,38 & 54,55 & 52,02 \\
\hline \multirow[t]{6}{*}{4} & $\begin{array}{l}\text { Kelahiran (ekor) (birth }(\%)) \\
\text { a. Jantan (ekor) (male) }\end{array}$ & $\begin{array}{r}161 \\
76\end{array}$ & $\begin{array}{l}6 \\
4\end{array}$ & $\begin{array}{l}42 \\
26\end{array}$ & $\begin{array}{l}5 \\
3\end{array}$ & $\begin{array}{l}654 \\
334\end{array}$ & $\begin{array}{l}1 \\
1\end{array}$ & $\begin{array}{l}869 \\
444\end{array}$ \\
\hline & $\begin{array}{l}\text { Terhadap induk (\%) (adult } \\
\text { female }(\%))\end{array}$ & 24,20 & 16,67 & 25,74 & 37,50 & 31,81 & 33,33 & 29,60 \\
\hline & $\begin{array}{l}\text { Terhadap populasi rata-rata }(\%) \\
\text { (birth total to average } \\
\text { population }(\%))\end{array}$ & 12,35 & 10,81 & 13,76 & 9,38 & 16,66 & 18,18 & 15,40 \\
\hline & b. Betina (ekor) (female) & 85 & 2 & 16 & 2 & 320 & 0 & 425 \\
\hline & $\begin{array}{l}\text { Terhadap induk (\%) (adult } \\
\text { female }(\%))\end{array}$ & 27,07 & 8,33 & 15,84 & 25,00 & 30,48 & 0,00 & 28,33 \\
\hline & $\begin{array}{l}\text { Terhadap populasi rata-rata (\%) } \\
\text { (birth total to average } \\
\text { population }(\%))\end{array}$ & 13,81 & 5,41 & 8,47 & 6,25 & 15,96 & 0,00 & 14,74 \\
\hline \multirow[t]{2}{*}{5} & $\begin{array}{l}\text { Tingkat kelahiran (birth rates) } \\
\text { a. Terhadap Induk (\%) (adult } \\
\text { female }(\%))\end{array}$ & 51,27 & 25,00 & 41,58 & 62,50 & 62,29 & 33,33 & 57,93 \\
\hline & $\begin{array}{l}\text { b. Terhadap populasi rata-rata (\%) } \\
\text { (birth total to average } \\
\text { population }(\%))\end{array}$ & 26,16 & 16,22 & 22,22 & 15,63 & 32,62 & 18,18 & 30,14 \\
\hline 6 & $\begin{array}{l}\text { Kematian ternak terhadap populasi } \\
(\%) \text { (livestock deaths to population } \\
(\%) \text { ) }\end{array}$ & 0,74 & 0,00 & 0,51 & 0,00 & 0,69 & 0,00 & 0,68 \\
\hline 7 & Natural increase (\%) (NI) & 25,42 & 16,22 & 21,71 & 15,63 & 31,93 & 18,18 & 29,46 \\
\hline
\end{tabular}

kali kawin $(\mathrm{S} / \mathrm{C}=1,63)$ pada kawin IB.

Rata-rata umur sapih pada sapi potong di Kabupaten Pesisir Selatan Provinsi Sumatera Barat adalah 5,57 bulan dan rata-rata jarak beranak adalah 16,20 bulan. Selanjutnya batas pemeliharaan pada sapi jantan adalah pada umur 2,41 tahun dan umur 6,55 tahun pada sapi betina dengan frekuensi beranak sebanyak 2,46 kali.

Pada penelitian ini rata-rata umur induk pertama kali melahirkan $33,83 \pm 1,30$ bulan dan dikawinkan kembali setelah beranak selama $5,30 \pm 0,51$ bulan dengan jarak beranak atau jarak antara dua kelahiran sebesar 16,20 $\pm 0,92$ bulan. Persentase kelahiran pedet jantan dan betina adalah $64,83 \pm 18,84 \%$ dan
$35,17 \pm 18,84 \%$. Kondisi induk setelah melahirkan rata-rata sedang yaitu sebesar $60,52 \%$, kurus sebesa 30,92\% dan gemuk sebesa $8,56 \%$. Berdasarkan data umur pertama kali kawin, induk pertama kali beranak, dan jarak kelahiran maka dapat dihitung nilai efisiensi reproduksi (ER) (Hardjosubroto, 1994) sebagai berikut:

$\mathrm{ER}=\frac{(16,20)(1)}{(33,83)-(23,02)+(16,20)-(9)} \times 100 \%=89,95 \%$

Induk yang beranak pertama kali lebih dari 27 bulan akan mempunyai nilai efisiensi reproduksi (ER) kurang dari $100 \%$ dan sebaliknya apabila kurang dari 27 bulan maka nilai efisiensi reproduksi (ER) akan lebih dari 
Tabel 6. Net replacement rate (NRR) sapi potong di Kabupaten Pesisir Selatan Provinsi Sumatera Barat tahun 2013 (net replacement rate of beef cattle in Pesisir Selatan District West Sumatera Province 2013)

\begin{tabular}{|c|c|c|c|c|c|c|c|c|}
\hline \multirow{2}{*}{$\begin{array}{l}\mathrm{N} \\
\mathrm{o}\end{array}$} & \multirow{2}{*}{ Peubah (variable) } & \multicolumn{6}{|c|}{ Bangsa (breed) } & \multirow{2}{*}{$\begin{array}{l}\text { Semua bangsa } \\
\text { (all breed })\end{array}$} \\
\hline & & Bali & $\mathrm{PO}$ & SimPO & SimPes & Pesisir & LimPO & \\
\hline \multirow[t]{4}{*}{1} & Jantan $($ male $)$ & & & & & & & \\
\hline & $\begin{array}{l}\text { a. Kebutuhan pejantan penganti } \\
(\%)(\text { necessity of male }(\%))\end{array}$ & 10,23 & 0,00 & 3,62 & 18,55 & 3,18 & 0,00 & 14,37 \\
\hline & $\begin{array}{l}\text { b. Ketersediaan Pejantan }(\%) \\
\text { (availability of male }(\%) \text { ) }\end{array}$ & 10,14 & 10,25 & 12,37 & 9,09 & 13,44 & 16,67 & 12,60 \\
\hline & Net replacement rate $(\%)$ & 99,12 & 0,00 & 341,71 & 49,00 & 422,68 & 0,00 & 87,68 \\
\hline \multirow[t]{4}{*}{2} & Betina $($ female $)$ & & & & & & & \\
\hline & $\begin{array}{l}\text { a. Kebutuhan betina pengganti } \\
(\%)(\text { necessity of female }(\%))\end{array}$ & 10,05 & 13,07 & 10,30 & 6,30 & 10,31 & 9,56 & 9,94 \\
\hline & $\begin{array}{l}\text { b. Ketersediaan betina }(\%) \\
\text { (availabilityoffemale }(\%) \text { ) }\end{array}$ & 11,32 & 5,13 & 7,42 & 6,06 & 12,85 & 0,00 & 12,03 \\
\hline & Net replacement rate $(\%)$ & 112,64 & 39,25 & 72,04 & 96,19 & 124,63 & 0,00 & 121,03 \\
\hline
\end{tabular}

100\%. Pada penelitian ini nilai efisiensi reproduksi yang diperoleh rendah, hal ini disebabkan umur pertama kali beranak relatif tinggi yaitu 33,83 bulan (Hardjosubroto, 1994).

\section{Pertambahan alami (natural increase)}

Nilai natural increase (NI) diperoleh dengan mengurangkan tingkat kelahiran dengan tingkat kematian dalam satu wilayah tertentu dalam waktu tertentu yang biasanya diukur dalam waktu satu tahun (Sumadi et al., 2001). Pada Tabel 5 menunjukkan perhitungan natural increase sapi potong di Kabupaten Pesisir Selatan Provinsi Sumatera Barat tahun 2013. Pada Tabel 5 menunjukkan rata-rata NI pada semua bangsa sapi potong sekitar 29,46\%. Nilai natural increase ini lebih tinggi dibandingkan dengan nilai natural increase pada penelitian Tanari et al. (2011) sebesar 12,13\% dan Susanti et al. (2015) sebesar24,39\%. Nilai NI per bangsa sapi potong yaitu sapi Bali sebesa 25,42\%, sapi PO sebesa $16,22 \%$, sapi SimPO sebesa $21,71 \%$, sapi SimPes sebesa $15,63 \%$, sapi Pesisir sebesa 31,93\% dan sapi LimPO sebesa $18,18 \%$. Sapi Pesisir pada penelitian ini mempunyai nilai NI yang relatif tinggi dari pada sapi Bali, sapi PO, sapi SimPO, sapi SimPes dan sapi LimPO. Hal ini diduga kondisi lingkungan Kabupaten Pesisir Selatan Provinsi Sumatera Barat merupakan ling- kungan yang sangat cocok untuk perkembangan sapi Pesisir. Selain itu, sapi Pesisir juga sudah terbiasa dengan kondisi pakan yang ada di Kabupaten Pesisir Selatan.

Rentang nilai NI antara $0,00-45,90 \%$ dengan rentang nilai NI untuk masing-masing kelas yaitu rendah dengan rentang nilai NI sebesar $0,00-15,00 \%$, sedang dengan rentang nilai NI sebesar $15,01-30,00 \%$ dan tinggi dengan rentang nilai NI sebesar 30,01 $45,90 \%$. Hasil penelitian menunjukan bahwa nilai NI sapi Pesisir tergolong tinggi sedangkan nilai NI pada sapi Bali, PO, SimPO, SimPes dan LimPO tergolong sedang.

\section{Perhitungan nilai net replacement rate}

Nilai net replacement rate (NRR) dihitung dari jumlah ketersediaan bibit dibagi kebutuhan bibit (pengganti) dikalikan 100\%. Nilai NRR digunakan untuk mengetahui apakah jumlah kelahiran pedet dapat menutupi kebutuhan ternak pengganti sehingga populasi diwilayah tersebut tetap seimbang. Jika nilai NRR $<100 \%$ maka kebutuhan ternak pengganti tidak terpenuhi, sebaliknya bila nilai NRR $>100 \%$ maka kebutuhan ternak pengganti terpenuhi (Sumadi et al., 2001).

Nilai NRR sapi potong di Kabupaten Pesisir Selatan Provinsi Sumatera Barat tahun 2013 seperti pada Tabel 6. Pada Tabel 6 menunjukkan nilai NRR pada semua sapi potong jenis kelamin jantan adalah 87,68\% 
Tabel 7. Potensi atau output sapi potong di Kabupaten Pesisir Selatan Provinsi Sumatera Barat tahun 2013 (output of beef cattle in Pesisir Selatan District of West Sumatera 2013)

\begin{tabular}{|c|c|c|c|c|c|c|c|c|}
\hline \multirow{2}{*}{ No } & \multirow{2}{*}{ Peubah (variable) } & \multicolumn{6}{|c|}{ Bangsa (breed) } & \multirow{2}{*}{ Rata-rata } \\
\hline & & Bali & $\mathrm{PO}$ & SimPO & SimPes & Pesisir & LimPO & \\
\hline & \multicolumn{8}{|l|}{ Output } \\
\hline 1 & \multicolumn{8}{|c|}{ Ternak afkir $(\%)$ (cattle culled) } \\
\hline & a. Jantan (male) & 10,23 & 0,00 & 3,62 & 18,55 & 3,18 & 0,00 & 5,93 \\
\hline & b. Betina (female) & 10,05 & 13,07 & 10,30 & 6,30 & 10,33 & 16,67 & 11,12 \\
\hline \multirow[t]{3}{*}{2} & \multicolumn{8}{|c|}{ Sisa replacement $(\%)$ (rest of replacement $(\%))$} \\
\hline & a. Jantan (male) & 1,00 & 10,25 & 9,57 & $-9,44$ & 11,30 & $-9,56$ & 2,19 \\
\hline & b. Betina (female) & 2,51 & 0,00 & 0,00 & 0,00 & 3,54 & 0,00 & 1,01 \\
\hline \multicolumn{2}{|c|}{ Jumlah $(\%)($ total $(\%))$} & 23,79 & 23,32 & 23,49 & 15,41 & 28,35 & 7,11 & 20,25 \\
\hline
\end{tabular}

dan betina $121,03 \%$, artinya ketersediaan sapi jantan untuk pengganti sebanyak 0,88 kali dari kebutuhan, pada sapi betina untuk pengganti sebanyak 1,2 kali dari kebutuhan, sehingga Kabupaten Pesisir Selatan Provinsi Sumatera Barat dapat dinyatakan kekurangan ternak sapi jantan. Hasil penelitian ini jauh lebih rendah dibandingkan nilai net replacement rate Susanti et al. (2015) yang memperoleh nilai net replacement rate sebesar $143,26 \%$ pada sapi jantan dan 220,15\% pada sapi betina. Hal ini kemungkinan disebabkan kecenderungan peternak menjual ternak jantan untuk menutupi kebutuhan pada saat masa sekolah tiba ataupun dijual pada saat hari raya Idul Fitri dan Idul Adha untuk mendapatkan harga yang lebih tinggi. Tingginya penjualan ternak jantan dibandingkan ternak betina dikarenakan ternak betina dipelihara untuk mendapatkan keturunan dan dikembangbiakan.

\section{Output}

Potensi atau output sapi potong di Kabupaten Pesisir Selatan Provinsi Sumatera Barat yaitu kemampuan wilayah tersebut untuk mengeluarkan sapi bibit maupun untuk dipotong tanpa mengganggu perkembangan populasi sapi potong di wilayah tersebut (Sumadi et al., 2011). Estimasi output dikategorikan tinggi apabila persentase kelahiran maksimal dan persentase kematian rendah, karena apabila nilai natural increase maksimal maka nilai output juga akan ikut maksimal. Output dapat terdiri atas sapi afkir (tua) jantan dan betina, sapi muda sisa pengganti jantan maupun betina.Berdasarkan pola pembiakan ternak tersebut, maka dapat dihitung komposisi potensi sapi potong di Kabupaten Pesisir Selatan Provinsi Sumatera Barat Tahun 2013. Pada Tabel 7 menyajikan potensi atau output sapi potong di Kabupaten Pesisir Selatan Provinsi Sumatera Barat.

Sapi-sapi afkir digemukan kemudian dipotong, sapi muda jantan untuk bakalan penggemukan dan sapi muda betina untuk bibit pengembangan populasi sapi potong diwilayah sendiri atau tempat lain. Secara rata-rata output sapi potong pada semua bangsa untuk sapi afkir jantan sebesar 5,93\% dan betina sebesar $11,12 \%$ dari populasi, sapi muda jantan sebesar $2,19 \%$ dan betina sebesar $1,01 \%$ dari populasi.

Pada penelitian ini sisa replacement atau output sapi SimPes muda jantan memiliki nilai $-9,44 \%$ dan sapi LimPO muda jantan memiliki nilai $-9,56 \%$, hal ini kemungkinan disebabkan jumlah populasi yang sedikit dan kecenderungan masyarakat untuk menjual ternak jantan sebelum umur dua tahun.

\section{KESIMPULAN}

Berdasarkan hasil penelitian maka dapat disimpulkan bahwa populasi sapi potong di Kabupaten Pesisir Selatan kekurangan ternak jantan sebesar $12,32 \%$ dengan nilai NRR jantan sebesar $87,68 \%$ dan kelebihan ternak betina sebesar $21,03 \%$ dengan nilai NRR betina sebesar $121,03 \%$. Komposisi sapi potong di kabupaten Pesisir Selatan terdiri dari $20,77 \%$ sapi Bali, $1,20 \%$ sapi PO, 6,05\% sapi SimPO, 1,01\% sapi SimPes, 70,78\% sapi Pesisir dan $0,18 \%$ sapi LimPO. Potensi atau output sapi potong tahun 2013 pada sapi Bali 
sebesar 23,79\% setara dengan 3.729 ekor, sapi PO sebesar 23,32\% setara dengan 211 ekor, sapi SimPO sebesar 23,49\% setara dengan 1.027 ekor, sapi SimPes sebesar 15,14\% setara dengan 116 ekor, sapi Pesisir sebesar 28,35\% setara dengan 15.136 ekor dan sapi LimPO sebesar 7,11\% setara dengan 10 ekor dengan rata-rata output sebesar 20,25\% setara dengan 20.174 ekor. Rata-rata output ternak afkir jantan sebesar 5,39\% dan ternak afkir betina sebesar $11,12 \%$ serta rata-rata sisa replacement ternak jantan sebesar 2,19\% dan sisa replacement ternak betina sebesar $1,01 \%$ dari populasi.

\section{DAFTAR PUSTAKA}

Badan Pusat Statistik. 2012. Pesisir Selatan Dalam Angka. BPS Kabupaten Pesisir Selatan, Painan.

Budiarto, A. 1991. Produktivitas sapi potong di Jawa Timur tahun 1988-1989. Tesis Program Pascasarjana Peternakan. Universitas Gadjah Mada, Yogyakarta.

Hardjosubroto, W. 1994. Aplikasi Pemuliabiakan Ternak di Lapangan. Jakarta: Grasindo.

Hardjosubroto, W. 1992. Pola pembiakan dan output sapi potong di Daerah Istimewa Yogyakarta. Buletin Peternakan 16:5462.

Hardjosubroto, W., P.A. Supriyono, D. Sularsasa, dan Sumadi. 1990. Persentase panen pedet (calf crop) pada sapi potong di Dati II Pati dan Purworejo Jawa Tengah. Laporan Penelitian. Fakultas Peternakan. Universitas Gadjah Mada, Yogyakarta.
Sumadi. 2001. Estimasi dinamika populasi dan output kambing peranakan Ettawah di Kabupaten Kulon Progo. Buletin Peternakan 25:161-171.

Sumadi, H. Mulyadi, T. Hartatik dan R.D. Mundingsari. 2011. Estimasi potensi pembibitan sapi potong di Kecamatan Wonosari Kabupaten Gunung Kidul Daerah Istimewa Yogyakarta. Laporan Hibah Penelitian Tematik Laboratorium. Fakultas Peternakan. Universitas Gadjah Mada, Yogyakarta.

Susanti, A.E, N. Ngadiyono dan Sumadi. 2015. Estimasi output sapi potong di Kabupaten Banyasin Provinsi Sumatera Selatan. Jurnal Peternakan Sriwijaya. (Desember 2015) 17-28

Tanari, M, Y. Duma, Y. Rusiyantono dan M. Mangun. 2011. Dinamika populasi sapi potong di Kecamatan Pamoa Utara Kabupaten Poso. J. Agrisains 12 (1):2429

Widiyanti, N. 1987. Ledakan Penduduk Menjelang Tahun 2000. Cetakan ke-1 Bina Aksara, Jakarta.

Wirdahayati, R.B. Arizal P.B. Batuah dan A. Bamualim. 2006. Suplementasi pakan menunjang produksi ternak kerbau penghasil dadih di Sumatera Barat. Prosiding. Seminar Nasional Peternakan. Revitalisasi Potensi Lokal untuk Mewujudkan Swasembada Daging 2010 dalam Kerangka Pembangunan Peternakan yang Berkelanjutan dan Peningkatan Kesejahteraan Masyarakat, Padang, 11 12 September 2006. 